\title{
Highly resolved distribution of aftershocks of the 2007 Noto Hanto Earthquake by a dense seismic observation
}

\author{
Shin'ichi Sakai ${ }^{1}$, Aitaro Kato ${ }^{1}$, Takashi Iidaka ${ }^{1}$, Takaya Iwasaki ${ }^{1}$, Eiji Kurashimo ${ }^{1}$, Toshihiro Igarashi ${ }^{1}$, Naoshi Hirata ${ }^{1}$, \\ Toshihiko Kanazawa ${ }^{1}$, and the group for the joint aftershock observation of the 2007 Noto Hanto Earthquake \\ ${ }^{1}$ Earthquake Research Institute, University of Tokyo, 1-1-1 Yayoi, Bunkyo-ku, Tokyo 113-0032, Japan
}

(Received July 8, 2007; Revised December 6, 2007; Accepted December 8, 2007; Online published February 19, 2008)

\begin{abstract}
The 2007 Noto Hanto Earthquake occurred on March 25, 2007, in the Noto Peninsula, central Japan. A half day after the main shock, we started installing temporary seismic stations in order to determine the precise locations of its aftershocks. Ten universities and two research institutes deployed 88 temporary seismic stations in and around the source area. The observation lasted for about 2 months. We relocated 1318 aftershocks with arrival time corrections at each station. The relocated hypocenters show relatively small errors-less than $0.2 \mathrm{~km}$ in the horizontal direction and less than $0.4 \mathrm{~km}$ depth. Most of the relocated hypocenters are about $2.0 \mathrm{~km}$ shallower than those determined by JMA. The distribution of the aftershocks forms a southeast-dipping plane. The main shock is located at the bottom part of their distribution. The precise aftershock distribution extends into a shallower area than the original, and it coincides with sea floor-ward extension of the active faults previously known from a sonic reflection survey. Heterogeneous distribution of the aftershocks on the fault plane shows low seismicity just above the main shock hypocenter, and middle-size aftershocks are distributed on the periphery of the main shock. A precursory event $(M 4.4)$ that occurred $0.6 \mathrm{~s}$ before the main rupture is located close to the $M 2.2$ foreshock that occurred 12 min before it.
\end{abstract}

Key words: 2007 Noto Hanto Earthquake, urgent aftershock observation, dense seismic array, precise aftershock distribution.

\section{Introduction}

An earthquake with a local body wave magnitude ( $M_{\text {jma }} 6.9, M_{\mathrm{w}} 7.1$ by USGS) occurred in the Noto Peninsula, central Japan, at 0:41, March 25, 2007 (UT) (Fig. 1). This earthquake was named the 2007 Noto Hanto Earthquake by the Japan Meteorological Agency (JMA). A JMA earthquake intensity of 6 upper was recorded in Nanao, Wajima and Anamizu. GPS measurements indicate that in Togi there was a crustal movement of about $21 \mathrm{~cm}$ in the southwestward direction and $7 \mathrm{~cm}$ in the upward direction. The maximum height of the accompanied tsunami was about $0.2 \mathrm{~m}$ at Kanazawa and Suzu. The event caused the destruction of as many as 33700 dwellings and one fatality, and left 338 people injured.

The two largest aftershocks, with a magnitude $M_{\text {jma }}$ of 5.4 , occurred at the northeast end of the aftershock region at 9:11 and on the southwest end at 22:16, on March 25, 2007 (UT). Although the earthquake generated many fissures and landslides, there was no clear evidence that any known faults on land were responsible for this earthquake. Some offshore active faults were reported off the Noto Peninsula (Katagawa et al., 2005), and they may be related to the present event. One of the main aims of this study is to clarify the relation between the offshore faults, the geological faults on lands, and the aftershock distribution.

Copyright (c) The Society of Geomagnetism and Earth, Planetary and Space Sciences (SGEPSS); The Seismological Society of Japan; The Volcanological Society of Japan; The Geodetic Society of Japan; The Japanese Society for Planetary Sciences; TERRAPUB.
A focal mechanism of the main shock determined by broadband waveforms indicates a thrust-type fault with northwest-southeast compression, while that from the firstmotion data contains prominent right-lateral strike slip (NIED, 2007). To understand the discrepancy, we carefully inspected the waveforms of the first part of the main shock to find a possible small amplitude forerunning arrival. The clarification of the relative location of the main shock hypocenter, that is to say, the initial point of the main rupture, the forerunning small rapture, and a foreshock which occurred 12 min before the main shock, in terms of the aftershock distribution, is another aim of the present study.

There are several seismic stations in and around the source region of the 2007 Noto Hanto Earthquake because Japan has one of the densest arrays of seismic stations in the world (Obara, 2002). Nonetheless, an average spacing of approximately $15 \mathrm{~km}$ between permanent telemetry stations is insufficient to precisely locate events shallower than $15 \mathrm{~km}$. Immediately after the main shock, we deployed a temporary seismic array in the epicenter region to obtain detailed aftershock distribution. The observations lasted for about 2 months. In the present study, we will show data from 70 seismographs; these data were recovered in the first month, although we finally installed 88 temporal stations in and around the source area for approximately 2 months. Analysis of the whole data set, including those from an ocean bottom observation (Yamada et al., 2008), will appear later for integrated understanding of the aftershock activity. 


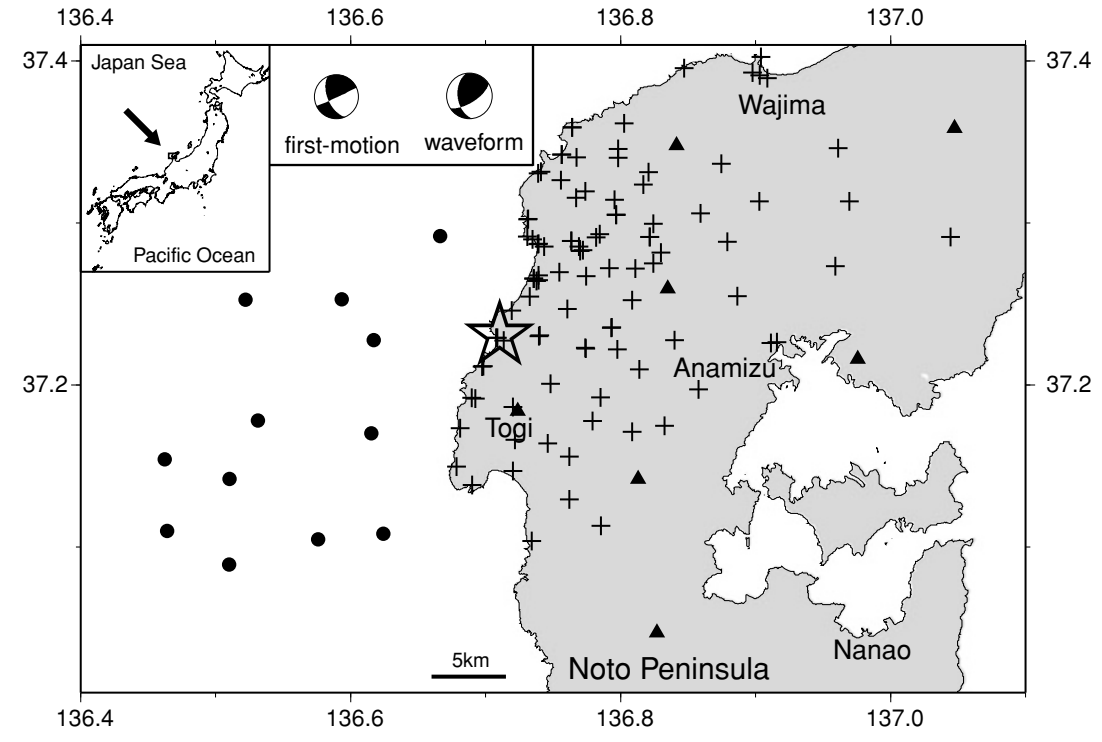

Fig. 1. Location map of the Noto Hanto Earthquake in 2007. The study area is indicated by a solid square (inset map). Cross, triangle, circle, and star indicate the position of the temporary seismic stations, the telemetered stations, the ocean bottom seismometers and the main shock, respectively. Inset indicates the focal mechanism determined by the first-motion data (left) and by broadband waveforms (right) by NIED.

\section{A Dense Seismic Network}

We started deploying seismographs on the day the main shock occurred and within 3 days (by March 28, 2007), 63 stations had been installed (Sakai et al., 2007). The number of stations increased to be 88 by April 18; the observations continued for about 1 month, including two telemetry stations and ocean bottom seismographic observations (Fig. 1). Although several types of seismographs were installed, most stations were equipped with a battery-operated recorder that continuously recorded a 3-component geophones signal at the sampling rate of 100 or $200 \mathrm{~Hz}$ (e.g., Shinohara et al., 1997).

\section{Hypocenter Determination}

We processed the continuously recorded field data according to the procedure used for the JMA unified seismic catalogue. $P$ - and $S$-wave arrival times were manually picked on a computer display (Urabe and Tsukada, 1991). We used a one-dimensional velocity model (Mikumo et al., 1988) for the located aftershocks with station corrections to take account of lateral changes in velocity (Table 1). We estimated station corrections, following the approach of Sakai et al. (2005). First, we estimated aftershock location, using a maximum-likelihood estimation algorithm (Hirata and Matsu'ura, 1987) and obtained residuals for the arrival times of $P$ - and $S$-waves. We assumed that the ratio of $P$ wave velocity $\left(V_{p}\right)$ to $S$-wave velocity $\left(V_{s}\right)$ was 1.73 . The average of the residuals was used as an initial value for the estimated station-correction for the calculated arrival time at each station. Next, we relocated the hypocenters with the estimated station corrections and calculated the travel time residuals for the relocated hypocenters. We relocated them again using new station-corrections calculated from the new residuals. This procedure was repeated five times to obtain average residuals of less than $0.01 \mathrm{~s}$. Finally, we obtained relocated aftershocks and station-corrections from the 70 temporary stations and 12 permanent stations in and
Table 1. $P$-wave velocity structure models used for hypocenter determination. $V_{p} / V_{s}$ is assumed to be 1.73 .

\begin{tabular}{cc}
\hline Depth $(\mathrm{km})$ & $P$-wave velocity $(\mathrm{km} / \mathrm{s})$ \\
\hline 0 & 5.40 \\
2 & 5.41 \\
3 & 6.00 \\
5 & 6.14 \\
14 & 6.26 \\
20 & 6.42 \\
28 & 6.91 \\
30 & 7.45 \\
44 & 7.75 \\
\hline
\end{tabular}

around the source area (Fig. 2).

We also relocated events that occurred before our temporary observation, including the main shock, the largest aftershocks, and a foreshock, by applying the station corrections already estimated in the above way. The station corrections reduced the root-mean-squares (rms) of the residuals in arrival times from $0.093 \mathrm{~s}$ to $0.038 \mathrm{~s}$ for $P$-wave arrivals and from 0.282 s to $0.086 \mathrm{~s}$ for $S$-wave arrivals. The masterevent method was then applied to relocate the main shock and the aftershocks that occurred before the temporary stations were deployed (Douglas, 1967). We selected those aftershocks as master events that were the nearest to the target events. We checked several events around the targets in the arrival-time domain so that relative arrival times among stations are similar to those for the target event. The relocated hypocenters of the main shock, a foreshock, and a precursory event are listed in Table 2. The other relocated events which occurred before the deployment of the temporary stations are shown in Fig. 3(e) and 3(f).

\section{Discussion}

We relocated 1318 events with a magnitude larger than 1.8 listed in the JMA catalogue for the period from 


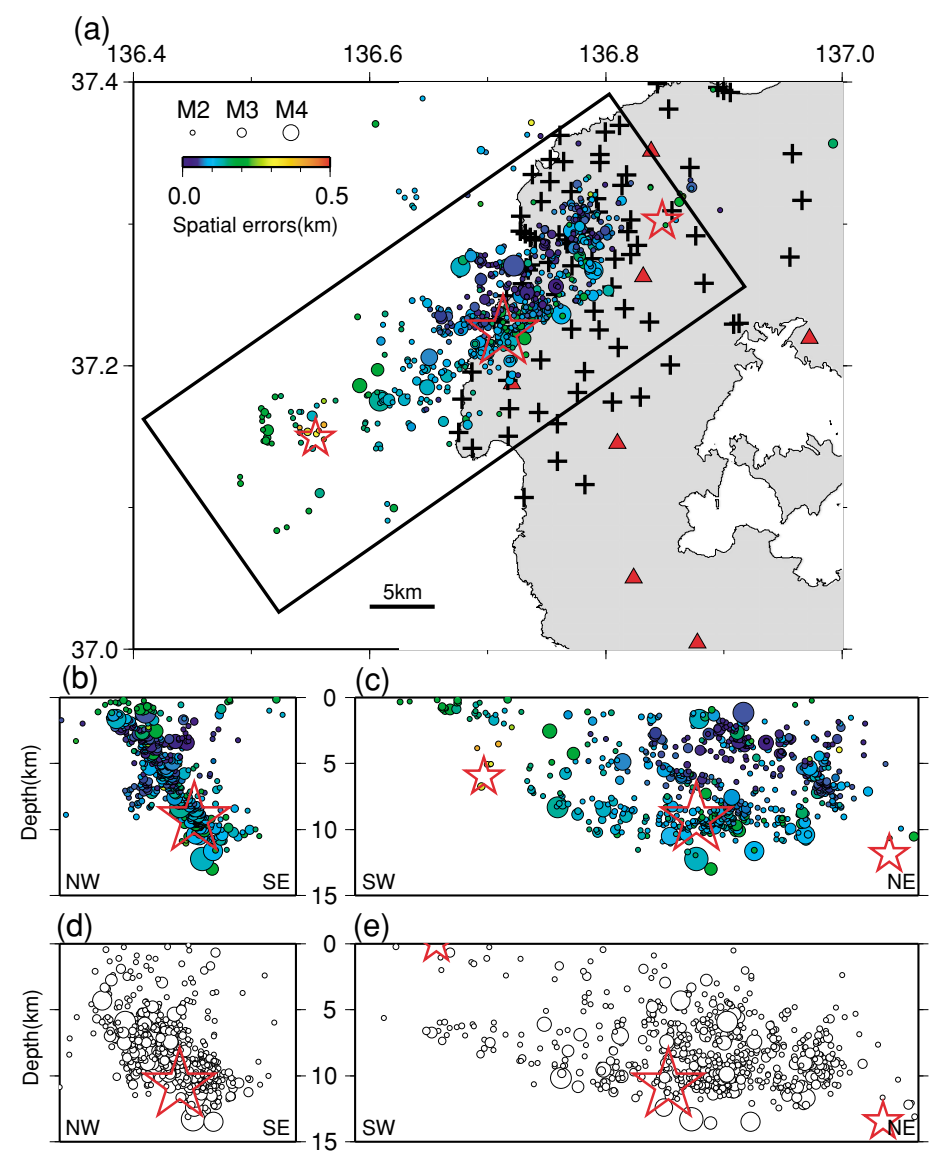

Fig. 2. (a) Distribution of aftershock of the Noto Hanto Earthquake in 2007 and temporary seismic stations. The triangles and the crosses represent the telemetered and temporary seismic stations, respectively. Large and small stars indicate the positions of the main shock and the two largest aftershocks, respectively. Only hypocenters with small spatial errors of less than $0.2 \mathrm{~km}$ in the horizontal direction and less than $0.4 \mathrm{~km}$ in depth are shown. Spatial errors of the aftershocks are shown by color, from blue for $0 \mathrm{~km}$ to red for $0.5 \mathrm{~km}$ : blue corresponds to better and red corresponds to worse. (b) Vertical cross section seen from the southwest. (c) Vertical cross section seen from the southeast. (d) Aftershocks reported in JMA unified catalogue on a vertical cross section seen from the southwest. (e) Aftershock reported in JMA unified catalogue on a vertical cross section seen from the southeast.

Table 2. Comparison hypocenters of the foreshock and the precursory event, and the main shock (main rupture). Times are in UT.

\begin{tabular}{ccccccccc}
\hline & date & H & M & S & Latitude (N) & Longitude (E) & Depth $(\mathrm{km})$ & $M$ \\
\hline Foreshock & $2007 / 3 / 25$ & 9 & 29 & 35.27 & 37.21664 & 136.69897 & 9.09 & 2.2 \\
Precusor & $2007 / 3 / 25$ & 9 & 41 & 58.39 & 37.21698 & 136.70192 & 9.62 & 4.4 \\
Main shock & $2007 / 3 / 25$ & 9 & 41 & 58.99 & 37.22368 & 136.71291 & 9.19 & 6.6 \\
\hline
\end{tabular}

March 25 and April 18. For further analysis, we selected 988 hypocenters with spatial standard errors (Hirata and Matsu'ura, 1987) of less than $0.2 \mathrm{~km}$ in the horizontal direction and less than $0.4 \mathrm{~km}$ in depth. The accuracy of the hypocenter determination is shown by color in Fig. 2.

The relocated hypocenters in this study are approximately $2.0 \mathrm{~km}$ shallower than those given by the JMA catalogue. In contrast, there is no large difference in epicenters between the relocated and the JMA catalogue because lateral heterogeneity of the velocity structure is small compared to areas with large heterogeneity, such as that in the 2004 Mid-Niigata Prefecture Earthquake (Sakai et al., 2005). Unlike the JMA catalogue, our hypocenters indicate some clusters. Some aftershocks are concentrated on the edge and the center of the aftershock distribution. There is a sparse distribution of aftershocks near the hypocenter of the main shock, that is, the nucleation point of the main shock rupture (e.g., Yamanaka, 2007). This sparse aftershock region roughly coincides with a large slip area obtained by the waveform analysis. The negative correlation between a large slip area of the main shock and a dense aftershock area has been reported for other large earthquakes in other studies with highly resolved aftershocks (e.g., Woessner et al., 2006).

The aftershocks are distributed to form a downward convex shape, with the deepest location below the hypocenter of the main shock. This feature coincides with the distribution of the Mid-Niigata Prefecture Earthquake (Iio et al., 2006). The two largest aftershocks occurred at the both ends of the distribution. The gap between the activity around the southwestern largest aftershock and the main aftershock distribution was gradually filled up over time, although the gap still remains at present beside the northeastern largest aftershock. 

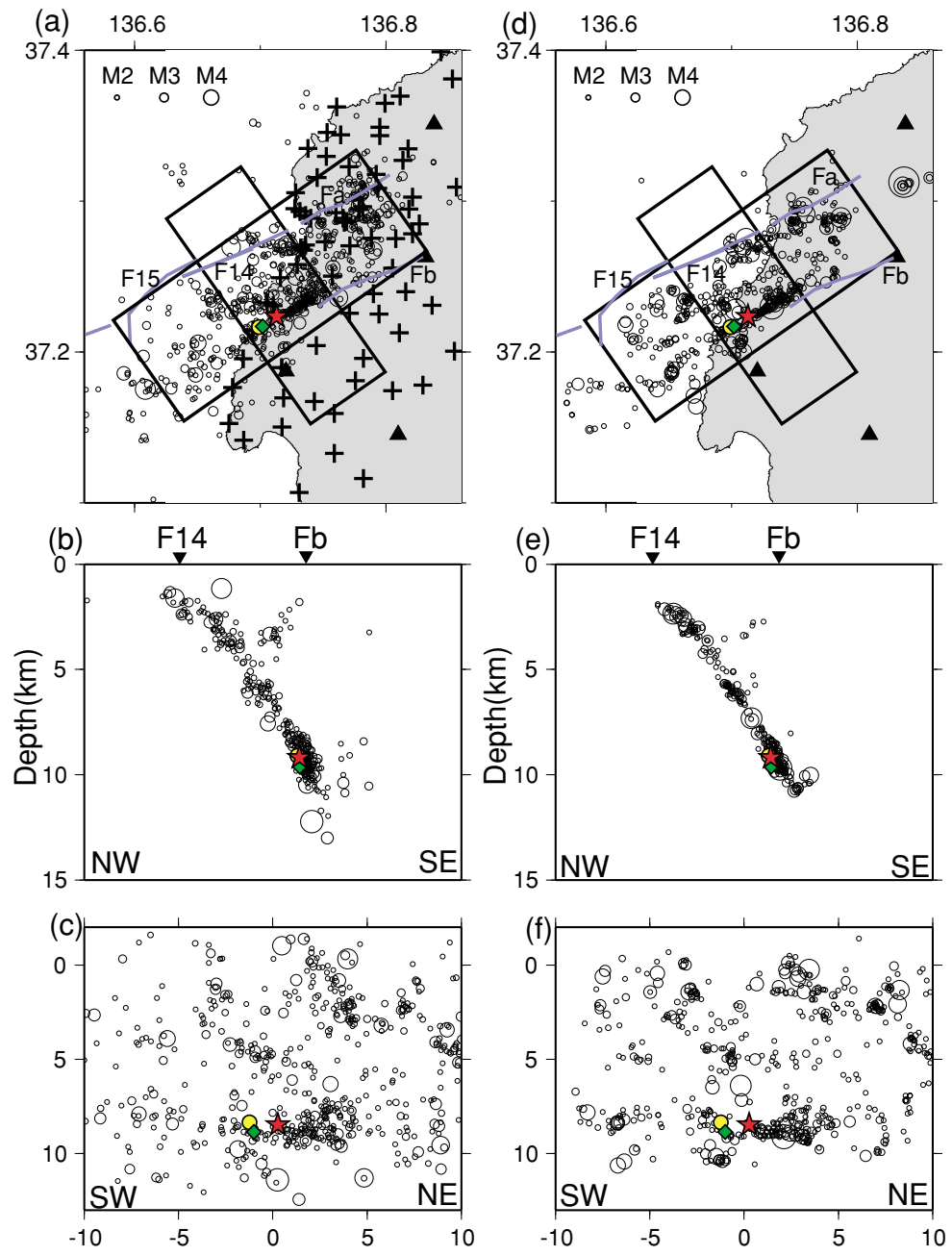

Fig. 3. (a) Distribution of the aftershocks relocated by temporary and telemeterd seismic stations data (March 25 to April 18, 2007). The crosses and triangles represent the temporary and the telemetered seismic stations, respectively. The red star shows the location of the main rupture. The offshore blue lines with $F 14$ and F15 indicate the positions of sea floor traces of the active faults of Katagawa et al. (2005) and the onshore lines show those of geological faults, $F a$ and $F b$ (Hokuriku District Eng. Geol. Mapping Com., 1990). (b) Vertical cross section seen from the southwest. The red star represents the hypocenter of the main rupture. (c) Vertical cross section seen from the southeast. (d) Epicenters of aftershocks (0:00-8:00 March 25, 2007) that occurred before the temporary stations were deployed with the starting point of the main rupture (red star). The triangles show the telemetered stations which are used to locate events. These hypocenters are determined by the master event method using the high precision aftershocks shown in (a). Sea text for detailes. (e) Epicenters of aftershocks (0:00-8:00 March 25, 2007) on a vertical cross section seen from the southwest. The red star represents the hypocenter of the main rupture. (f) Epicenters of aftershocks (0:00-8:00 March 25, 2007) on a vertical section seen from the southeast. Position of the starting point of the main rupture (red star), the 0.6-s before the precursory event (green diamond), and 12-min before foreshock (yellow circle) are shown.

Aftershocks around the main shock form a thin plane dipping southeast with a high-angle $\left(60^{\circ}\right)$ (Fig. 3). They were distributed in a depth range from 2 to $13 \mathrm{~km}$ and a lateral length of approximately $30 \mathrm{~km}$. In the cross section seen from the southwest, there is a bending point of the distribution at a depth of approximately $9 \mathrm{~km}$ (Fig. 3(b)). The hypocenter of the main shock, that is, the initial rupture point of the main shock, is located at the bending point. We conclude that the southeast-dipping plane represents the source fault plane of the main shock and that the rupture started at the deep end of this distribution, because the dip angle of the major distribution is consistent with a thrust fault mechanism obtained by waveform analysis.

Although no active faults on land have been reported on the shallower extension of the aftershock distribution, some geological faults ( $F a$ and $F b$ in Fig. 3) have been reported (Hokuriku district engineering geological mapping commit- tee, 1990). Furthermore, offshore active faults were documented by a sonic reflection survey (F14 and F15 of Katagawa et al., 2005). We can see that the F14 fault is located exactly on the extension of the southeast-dipping distribution and that the strike of the $F 14$ fault corresponds to that of the fault plane of the focal mechanism. This result strongly suggests that the offshore active faults are responsible for the present event although very shallow aftershocks did not occur, leaving no direct observations of the rupture on seafloor to confirm it. There is also a northwest-dipping distribution with a depth range from 2 to $4 \mathrm{~km}$ whose shallower extension coincides with the geological fault $F b$. Note that the activity started right after the main shock occurrence (Fig. 3(e)), indicating a rapid stress transfer which might reactivate shallow geological structures.

There is a vertical distribution just below the starting point of the main shock rupture in a depth range between 


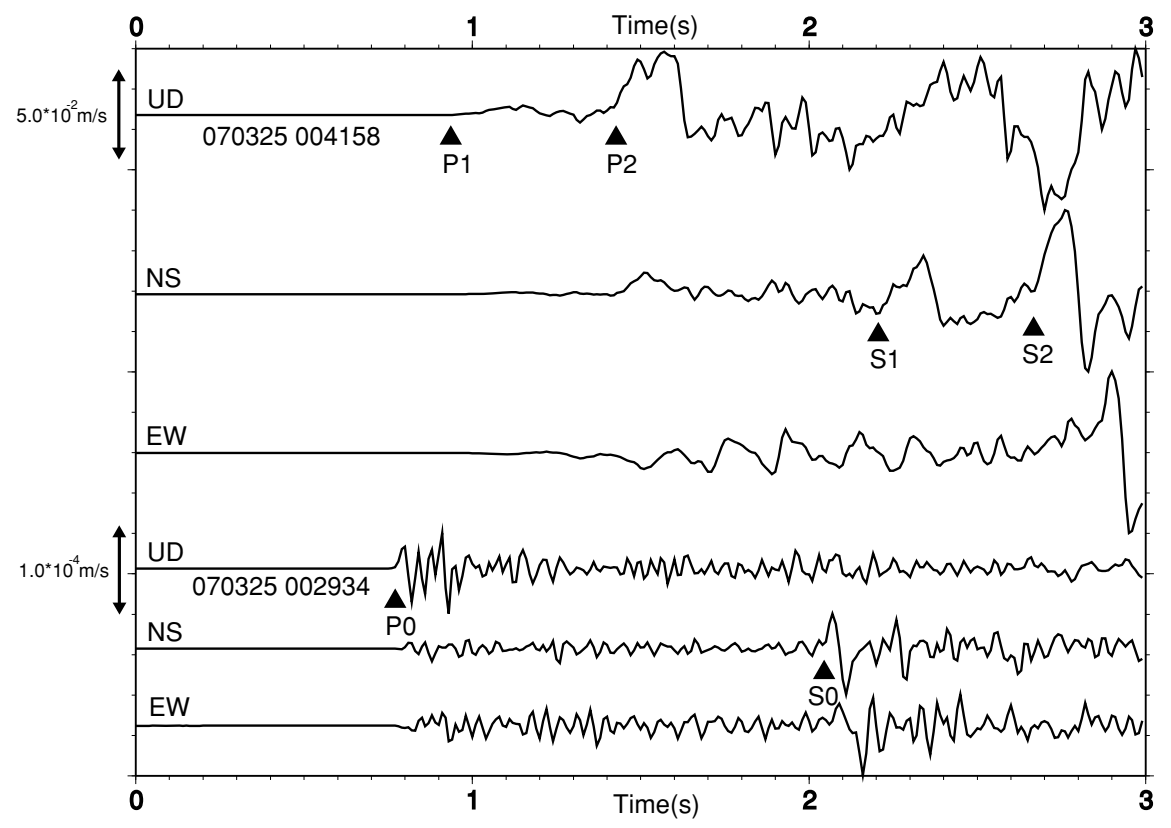

Fig. 4. Waveforms of the main shock and the foreshock at TGIH. Three top lines indicate the UD, NS, and EW components of the main shock for $3 \mathrm{~s}$, respectively. Three bottom lines indicate 3 -components of the foreshock. $P 0, P 1$, and $P 2$ indicate the first arrival of the $P$-wave of the foreshock, the precursory event, and the main rupture of the main shock, respectively. $S 0, S 1$ and $S 2$ indicate the first arrivals of the $S$-wave.

9 and $11 \mathrm{~km}$ and a lateral width of $2 \mathrm{~km}$ (Fig. 3(c)). A small but clear initial phase of the main shock was observed $0.6 \mathrm{~s}$ before the main phase of the main shock at many stations (Fig. 4). The newly determined distribution is important to our understanding of this initial phase. We picked arrival times and amplitudes at 16 stations to locate a hypocenter and estimate a magnitude of the precursory event: the event is estimated to have a magnitude of 4.4 and to be located about $1.2 \mathrm{~km}$ southwest of the starting point of the main rupture, as determined by the master event method. A focal mechanism of the precursory event has a strike slip component with one vertical nodal plane. We thus conclude that the focal mechanism with a prominent strike-slip component reported for the main shock by the first motion data corresponds to that of the initial phase (i.e., precursory rupture), and that the focal mechanism from the waveform data corresponds to the main rupture phase. If the vertical distribution below the main shock hypocenter corresponds to the precursory rupture, the fault size is about $2 \times 3 \mathrm{~km}$ from the distribution. It is interesting to compare relative locations among the starting points of the main rupture (hypocenter of the main shock, $\left.M_{\mathrm{jma}} 6.9, M_{\mathrm{w}} 7.1\right)$, the precursory events ( $M$ 4.4), and the 12-min-before foreshock ( $M$ 2.2). We found that the foreshock is closer to the precursory event than the main shock hypocenter: the foreshock is located about $300 \mathrm{~m}$ west of and $500 \mathrm{~m}$ shallower than the precursory event while the hypocenter of the main shock is $1200 \mathrm{~m}$ northeast of and $400 \mathrm{~m}$ shallower than the precursory event (Table 2). Though the focal mechanism of the foreshock failed to be estimated, it seems to be similar to that of the precursory. The proximity of the foreshock to the precursory event is important to understanding the triggering mechanism of the present events, and a further detailed studies will be necessary.

The estimated station correction for $P$-times ranges from
-0.2 and $+0.2 \mathrm{~s}$ and that for $S$-times from -0.7 and $0.1 \mathrm{~s}$. The northern stations have generally negative station corrections, small positive values for the southern stations, and relatively large positive values for the central stations. The station corrections indicate a low-velocity zone in the northern part and a high-velocity zone in the central area. The boundary between the low- and high-velocity zones is located on the main shock fault zone estimated by the distribution of the aftershock. Tomographic analysis of the data obtained by the present observation also shows lateral change in velocity across the distribution of aftershocks (Kato et al., 2008, this issue). The value of the stationcorrections are, however, smaller than those for the 2004 Mid-Niigata Prefecture Earthquake (Sakai et al., 2005).

\section{Conclusion}

The 2007 Noto Hanto Earthquake occurred on March 25, 2007, in the Noto Peninsula, central Japan. A half day after the main shock, we started installing temporary seismic stations in order to determine the precise distribution of the aftershocks. Ten universities and two research institutes deployed 88 temporary seismic stations in and around the source area. We relocated 1318 aftershocks with arrival time corrections at each station. We selected 988 hypocenters with spatial standard errors of less than $0.2 \mathrm{~km}$ in the horizontal direction and less than $0.4 \mathrm{~km}$ in depth. We found that the relocated hypocenters are about $2.0 \mathrm{~km}$ shallower than those determined by JMA. The distribution of aftershocks forms a sharp southeast-dipping plane. The main shock is located at a deep part of the distribution of aftershocks. The precise aftershock distribution indicates that the shallower extension of the source area coincides with the extension of active faults towards sea floor previously known from a sonic reflection survey. The heterogeneous distribution of the aftershocks on the fault shows low seis- 
micity just above the main shock hypocenter. Middle-size aftershocks are distributed on the periphery of the source area of the main shock. A precursory event $(M$ 4.4) that had occurred $0.6 \mathrm{~s}$ before the main shock is located close to the $M 2.2$ foreshock that had occurred 12 min before the main shock.

Acknowledgments. Many persons were involved in the preparation, deployment and recovery of field equipment in this important study. We express our special gratitude to Masaru Kobayashi, Toshio Haneda, Izumi Ogino, Shigeru Watanebe, Mamoru Saka, Koji Miyakawa, Atsushi Watanabe, Reiko Miura, Katsumi Miura, and Kiyoko Tagami for their picking the arrival times. Helpful comments given us by two reviewers, Dr. Uehira and Dr. Huang, and two editors, Prof. Yomogida and Dr. Iidaka, for the improvement of the manuscript are sincerely acknowledged. The group for the joint aftershock observation of the 2007 Noto Hanto Earthquake is composed of Hokkaido University, Hirosaki University, Tohoku University, Chiba University, University of Tokyo, Nagoya University, Kanazawa University, Kyoto University, Kyusyu University, Kagoshima University, National Research Institute for Earth Science and Disaster Prevention and National Institute of Advanced Industrial Science and Technology. Most of the figures were created using GMT (Wessel and Smith, 1995). This research was partially supported by the Ministry of Education, Science, Sports and Culture (MEXT), Grant-in-Aid for Special Purposes, 19900001, 2007, and the Special Coordination Funds for the Promotion of Science and Technology (MEXT) under the title of an urgent research for the 2007 Noto Hanto Earthquake. The work is conducted as a part of the 2 nd new program of research and observation for earthquake prediction (2004 to 2008).

\section{References}

Douglas, A., Joint epicenter determination, Nature, 215, 47-48, 1967.

Hirata, N. and M. Matsu'ura, Maximum-likelihood estimation of hypocenter with origin time eliminated using nonlinear inversion technique, Phys. Earth Planet. Inter., 47, 50-61, 1987.

Hokuriku District Eng. Geol. Mapping Com., Engineering Geological Map and manual of Hokuriku District $(1: 200,000)$, Kokudo Kaihatsu Gijyutsu Center, 1990.

Iio, Y., S. Matsumoto, T. Matsushima, K. Uehira, H. Katao, S. Ohmi, T. Shibutani, F. Takeuchi, K. Nishigami, B. Enescu, I. Hirose, Y. Kano, Y. Mamada, M. Miyazawa, K. Tatsumi, H. Wada, Y. Kohno, M. Korenaga, T. Ueno, and Y. Yukutake, Generating process of the 2004 Mid Niigata Prefecture Earthquake? Based on the results from the joint online aftershock observation, Zisin, 58, 463-475, 2006.

Katagawa, H., M. Hamada, S. Yoshida, H. Kadosawa, A. Mitsuhashi, Y. Kono, and Y. Kinugasa, Geological development of the west sea area of the Noto Peninsula district in the Neogene Tertiary to Quaternary, central Japan, J. Geogr., 114, 791-810, 2005.

Kato, A., S. Sakai, T. Iidaka, T. Iwasaki, E. Kurashimo, T. Igarashi, N.
Hirata, T. Kanazawa, and Group for the aftershock observations of the 2007 Noto Hanto Earthquake, Three-dimensional velocity structure in the source region of the Noto Hanto Earthquake in 2007 imaged by a dense seismic observation, Earth Planets Space, 60, this issue, 105$110,2008$.

Mikumo, T., H. Wada, and M. Koizumi, Seismotectonics of the Hida region, central Japan, Tectonophysics, 147, 95-119, 1988.

National Research Institute for Earth Science and Disaster Prevention (NIED), Earthquake mechanism information, http://www.hinet. bosai.go.jp/topics/niigata070716/, 2007.

Obara, K., S. Hori, K. Kasahara, Y. Okada, and S. Aoi, Hi-net: High sensitivity seismograph network in Japan, EOS Trans. AGU, 81(48), Fall Meet. Suppl., Abstract S71A-04, 2002.

Sakai, S., N. Hirata, A. Kato, E. Kurashimo, T. Iwasaki, and T. Kanazawa, Multi-fault system of the 2004 Mid-Niigata Prefecture Earthquake and its aftershocks, Earth Planets Space, 57, 417-422, 2005.

Sakai, S., A. Kato, E. Kurashimo, T. Iidaka, T. Igarashi, N. Hirata, T. Iwasaki, T. Kanazawa, S. Watanabe, T. Haneda, M. Kobayashi, K. Miura, R. Miura, K. Tagami, I. Ogino, M. Saka, A. Watanabe, K. Miyakawa, K. Katsumata, H. Takahashi, M. Kasahara, R. Honda, T. Maeda, M. Ichiyanagi, T. Yamaguchi, M. Kosuga, T. Okada, J. Nakajima, S. Hori, T. Nakayama, K. Nii, A. Hasegawa, T. Kono, S. Suzuki, N. Tsumura, R. Kobayashi, K. Nozaki, Y. Hiramatsu, K. Sugaya, A. Hayashi, T. Hirose, A. Sawada, K. Tanaka, Y. Yamanaka, H. Nakamichi, T. Okuda, Y. Iio, K. Nishigami, M. Miyazawa, H. Wada, N. Hirano, S Nakao, H. Katao, S. Ohmi, K. Ito, T. Shibutani, Y. Kano, I. Doi, S. Noda, T. Katagi, Y. Nishitsuji, S. Matsumoto, K. Matsushima, A. Saiga, H. Miyamachi, K. Imanishi, Y. Kuwahara, I. Cho, M. Hoshino, T. Takeda, Y. Asano, Y. Yukutake, T. Ueno, T. Maeda, T. Matsuzawa, S. Sekine, M. Matsubara, and K. Obara, Aftershock observation for the Noto Hanto Earthquake in 2007, Bull. Earthq. Res. Inst., 2007 (in Japanese).

Shinohara, M., N. Hirata, and S. Matsuda, Long-term low-power DAT seismic digital data recorder with GPS clock, Zisin, 50, 119-124, 1997 (in Japanese with English abstract).

Urabe, T. and S. Tsukada, A workstation-assisted processing system for waveform data from microearthquake networks, Abstracts of Spring Meeting of Seismological Society of Japan, 70, 1991 (in Japanese).

Wessel, P. and W. H. F. Smith, New version of the generic mapping tools released, EOS Trans. AGU, 76, 329, 1995.

Woessner, J., D. Schorlemmer, S. Wiemer, and P. M. Mai, Spatial correlation of aftershock locations and on-fault main shock properties, $J$. Geophys. Res., 111, B08301, doi:10.1029/2005JB003961, 2006.

Yamada, T., K. Mochizuki, M. Shinohara, T. Kanazawa, A. Kuwano, K. Nakahigashi, R. Hino, K. Uehira, T. Yagi, N. Takeda, and S. Hashimoto, Aftershock observation of the Noto Hanto earthquake in 2007 using ocean bottom seismometers, Earth Planets Space, 2008 (submitted).

Yamanaka, Y., EIC Seismological Note, http://www.eri.u-tokyo.ac.jp/ sanchu/Seismo_Note/2007/EIC185.html, 2007 (in Japanese).

S. Sakai (e-mail: coco@eri.u-tokyo.ac.jp), A. Kato, T. Iidaka, T. Iwasaki, E. Kurashimo, T. Igarashi, N. Hirata, T. Kanazawa, and the group for the joint aftershock observation of the 2007 Noto Hanto Earthquake 